\title{
PERENCANAAN JARINGAN IRIGASI BATANG ASAI KABUPATEN SAROLANGUN
}

\author{
Fransiska Febby N. P, Azwarman \\ Program Studi Teknik Sipil Universitas Batanghari \\ warman2789@gmail.com
}

\begin{abstract}
Abstrak
Upaya pemerintah dalam memenuhi kebutuhan pangan khususnya beras telah dilakukan diantaranya melalui program pembangunan jaringan irigasi. Untuk dapat mengalirkan air dari bendung ke areal lahan irigasi maka diperlukan suatu jaringan irigasi. Pembangunan jaringan irigasi Batang Asai di Kabupaten Sarolangun merupakan salah satu kegiatan pembangunanan penunjang irigasi di Provinsi Jambi. Dengan potensi persawahan yang luas, diharapkan daerah irigasi ini akan menjadi lumbung padi khususnya bagi Kabupaten Sarolangun dan umumnya bagi Provinsi Jambi. Dari hasil analisa ketersediaan air dengan Metode F. J. Mock diketahui besarnya debit andalan pada Daerah Irigasi Batang Asai Kabupaten Sarolangun dapat memenuhi kebutuhan air untuk areal pertanian $>1500 \mathrm{Ha}$, dengan sumber air berasal dari sungai Batang Asai yang mempunyai luas DPS secara keseluruhan $\pm 1262,4 \mathrm{~km}^{2}$ dan panjang sungai utamanya $\pm 104,1$ $\mathrm{km}$ untuk mewujudkan harapan Pemerintah menjadikan daerah ini sebagai lumbung padi dan meningkatkan ketahanan pangan nasional.
\end{abstract}

Kata Kunci:Jaringan Irigasi, Ketersediaan Air, Kebutuhan Air, Areal Pertanian

\section{PENDAHULUAN}

Pertumbuhan penduduk di Indonesia yang sangat pesat disatu sisi menimbulkan suatu permasalahan yaitu meningkatnya kebutuhan akan bahan pangan, sehingga perlu dipikirkan berbagai usaha untuk lebih meningkatkan hasil pertanian. Salah satu faktor dari pada usaha peningkatan produksi pangan khususnya padi adalah tersedianya air irigasi di sawah-sawah sesuai dengan kebutuhan. Upaya pemerintah dalam memenuhi kebutuhan pangan khususnya beras telah dilakukan diantaranya melalui program pembangunan jaringan irigasi. Untuk dapat mengalirkan air dari bendung ke areal lahan irigasi maka diperlukan suatu jaringan irigasi. Pembangunan jaringan irigasi Batang Asai di Kabupaten Sarolangun merupakan salah satu kegiatan pembangunan bangunan penunjang irigasi di Provinsi Jambi. Dengan potensi persawahan yang luas, diharapkan daerah irigasi ini akan menjadi lumbung padi khususnya bagi Kabupaten Sarolangun dan umumnya bagi Provinsi Jambi. Diperlukan pemberian sarana dan prasarana irigasi agar dapat meningkatkan produksi padi di wilayah tersebut dan meningkatkan ketahanan pangan Kabupaten Sarolangun dan penulis pun tertarik untuk mengangkatnya menjadi topic penelitian dengan judul "Perencanaan Jaringan Irigasi Batang Asai Kabupaten Sarolangun”.

\section{LANDASAN TEORI}

Curah Hujan Rencana

Curah hujan rencana adalah perkiraan besar curah hujan yang terjadi dalam periode ulang tertentu. 
1) Distribusi Probabilitas Gumbel

Perhitungan hujan rencana berdasarkan Distribusi Probabilitas Gumbel dilakukan dengan rumus berikut:

Dimana:

$$
\begin{aligned}
& \mathrm{X}_{\mathrm{T}}=\overline{\mathrm{X}}+\frac{S}{S_{n}}\left(\mathrm{Y}_{\mathrm{t}}-\mathrm{Y}_{\mathrm{n}}\right) \\
& \mathrm{S}=\sqrt{\frac{\sum\left(\mathrm{X}_{\mathrm{i}}-\overline{\mathrm{X}}\right)^{2}}{\mathrm{n}-1}}
\end{aligned}
$$

$\mathrm{X}_{\mathrm{T}}=$ hujan rencana atau debit dengan periode ulang $\mathrm{T}(\mathrm{mm})$

$\overline{\mathrm{X}}=$ nilai rata-rata dari data hujan $(\mathrm{mm})$

$\mathrm{S}=$ standar deviasi dari data hujan

$\mathrm{S}_{\mathrm{n}}=$ Reduced Standart Deviation

$\mathrm{Y}_{\mathrm{t}}=$ Reduced Variate

$\mathrm{Y}_{\mathrm{n}}=$ Reduced Mean

2) Distribusi Probabilitas Log Pearson Type III

Perhitungan hujan rencana berdasarkan Distribusi Probabilitas Log Pearson Type III dilakukan dengan rumus berikut:

Dimana:

$$
\log X_{T}=\log \bar{X}+K_{T} \times S \log X
$$

$\log X_{T}=$ nilai logaritmis hujan rencana dengan periode ulang $\mathrm{T}$

$\log \bar{X}=$ nilai rata-rata dari $\log$

$$
\mathrm{X}=\frac{\sum_{\mathrm{i}=1}^{\mathrm{n}} \log \left(\mathrm{X}_{\mathrm{i}}\right)}{\mathrm{n}}
$$

$S \log X=$ deviasi standar dari $\log X$

$S \log X=\sqrt{\frac{\sum(\log (\mathrm{Xi})-\log \overline{\mathrm{X}})^{2}}{\mathrm{n}-1}}$

$\mathrm{K}_{\mathrm{T}} \quad=$ variabel standar, besarnya bergantung koefisien kemencengan (Cs atau $\mathrm{G})$

Cs $\quad=\frac{n \sum(\log (\mathrm{X})-\log \overline{\mathrm{X}})^{3}}{(\mathrm{n}-1)(\mathrm{n}-2)(\mathrm{S} \log \overline{\mathrm{X}})^{3}}$

\section{Debit Andalan}

Perhitungan debit andalan bertujuan untuk menentukan areal daerah irigasi yang dapat diairi. Perhitungan debit andalan dengan metode Dr.F.J.Mock (Suripin, 2004) dapat dilakukan dengan rumus sebagai berikut:

Debit Efektif $=\frac{\text { aliran sungai } \times \frac{\mathrm{CA}}{1000} \times 10^{6}}{1 \text { bulan dalam detik }}$

Dimana CA adalah luas daerah aliran sungai.

\section{Kebutuhan Air Irigasi}

Kebutuhan air irigasi adalah jumlah volume air yang diperlukan untuk memenuhi kebutuhan evapotranspirasi, kehilangan air, kebutuhan air untuk tanaman dengan memperhatikan jumlah air yang diberikan oleh alam melalui hujan dan kontribusi air tanah. Kebutuhan air di sawah dapat dihitung dengan rumus sebagai berikut:

Untuk Padi: NFR = Etc+P-Re+WLR

Untuk Palawija: NFR = Etc - Re

Dimana:

Etc $=$ penggunaan air konsumtif $(\mathrm{mm} /$ hari $)$

$\mathrm{P} \quad=$ kehilangan air akibat perkolasi $(\mathrm{mm} / \mathrm{hari})$ 
$\operatorname{Re}=$ curah hujan efektif ( $\mathrm{mm} / \mathrm{hari})$

$\mathrm{WLR}=$ penggantian lapisan $\operatorname{air}(\mathrm{mm} / \mathrm{hari})$

\section{Penggunaan Air Konsumtif}

Penggunaan air konsumtif adalah jumlah total air yang dikonsumsi tanaman untuk penguapan (evaporasi), transpirasi dan aktivitas metabolisme tanaman, dengan rumus:

Etc $=$ Eto $\mathrm{x} \mathrm{kc}$

Dimana:

Eto $=$ evapotranspirasi tanaman $(\mathrm{mm} / \mathrm{hari})$

$\mathrm{kc}=$ koefisien tanaman

\section{Evapotranspirasi}

Evapotranspirasi adalah peristiwa berubahnya air menjadi uap ke udara bergerak dari permukaan tanah, permukaan air dan penguapan melalui tanaman. Jika air yang tersedia dalam tanah cukup banyak maka evapotranspirasi itu disebut Evapotranspirasi potensial. Metode Penmann modifikasi merupakan salah satu cara yang tepat untuk mendapatkan nilai evapotranspirasi potensial dengan rumus sebagai berikut:

Eto $=\mathrm{C} \times[\mathrm{W} \times \mathrm{Rn}+(1-\mathrm{W}) \times \mathrm{f}(\mathrm{u}) \times($ ea-ed $)]$

\section{Hujan Efektif}

Hujan efektif adalah hujan yang betul-betul dapat dimanfaatkan oleh tanaman selama masa pertumbuhannya baik langsung maupun tidak langsung. Untuk tanaman padi :

$\operatorname{Re}=0.7 \times \frac{1}{15} \times R_{80}$ (mm/bulan)

Untuk tanaman palawija :

$\operatorname{Re}=0.7 \times \frac{1}{15} \times R_{50}$ (mm/bulan)

Adapun penetapan nilai curah hujan $\mathrm{R}_{80}$ dan $\mathrm{R}_{50}$ adalah sebagai berikut:

$\mathrm{R}_{80}=\mathrm{n} / 5+1$

$\mathrm{R}_{50}=\mathrm{n} / 2+1$

Dimana:

$\mathrm{Re} \quad=$ hujan efektif tanaman $(\mathrm{mm})$

$\mathrm{R}_{80}$ dan $\mathrm{R}_{50}=$ hujan rancangan dengan probabilitas $80 \%$ dan $50 \%(\mathrm{~mm})$

$\mathrm{n} \quad=$ jumlah data

\section{Penyiapan Lahan}

Penyiapan lahan merupakan awal dari penggarapan lahan sawah untuk membajak dan melunakkan bagian atas lapisan tanah, pada waktu menanam padi. Untuk penanaman palawija dalam hal ini faktor penyiapan lahan tidak diperhitungkan.

$$
\begin{aligned}
\text { Eo } & =1,1 \times \text { Eto } \\
\mathrm{M} & =\mathrm{Eo}+\mathrm{P} \\
\mathrm{k} & =\mathrm{M} \times(\mathrm{T} / \mathrm{S}) \\
\mathrm{IR} & =\mathrm{M}\left(\frac{\mathrm{e}^{\mathrm{k}}}{\mathrm{e}^{\mathrm{k}}-1}\right)
\end{aligned}
$$

Dimana:

Eo $=$ evaporasi air terbuka selama masa penyiapan lahan $(\mathrm{mm} / \mathrm{hari})$ 
$\mathrm{M}=$ kebutuhan air untuk mengganti air yang hilang akibat evaporasi dan perkolasi di sawah yang telah dijenuhkan $(\mathrm{mm} / \mathrm{hr})$

$\mathrm{P} \quad=$ kehilangan air akibat perkolasi $(\mathrm{mm} / \mathrm{hari})$

$\mathrm{T}=$ jangka waktu penyiapan lahan $(\mathrm{mm} / \mathrm{hari})$

$\mathrm{S} \quad=$ air yang dibutuhkan untuk penjenuhan ditambah dengan $50 \mathrm{~mm}$

IR = kebutuhan air irigasi ditingkat persawahan $(\mathrm{mm} / \mathrm{hari})$

$\mathrm{e} \quad=$ konstanta $=2,718$

$\mathrm{k}=$ koefisien tanaman

\section{Debit Rencana}

Debit rencana adalah jumlah air per satuan waktu yang direncanakan untuk dialirkan. Untuk mengetahui besarnya debit rencana, terlebih dahulu perlu dihitung kebutuhan air di sawah dan kehilangan air yang mungkin terjadi. Debit rencana sebuah saluran dihitung dengan rumus umum berikut:

Dimana:

$$
\mathrm{Q}=\frac{\mathrm{NFRA}}{\mathrm{e}}
$$

$\mathrm{Q}=$ Debit rencana $\left(\mathrm{m}^{3} / \mathrm{dt}\right)$

$\mathrm{NFR}=$ Kebutuhan bersih air di sawah (ltr/dt/ha)

$\mathrm{A}=$ Luas daerah yang diairi (ha)

$\mathrm{e} \quad=$ efisiensi irigasi secara keseluruhan $(0,65)$

\section{METODOLOGI PENELITIAN}

Lokasi studi terletak di Dusun Berau Kecamatan Cermin Nan Gedang Kabupaten Sarolangun. Secara geografis, Kabupaten Sarolangun terletak antara 01 ${ }^{\circ} 53$ '39' sampai 02 $46^{\prime}$ '02" Lintang Selatan dan antara $102^{\circ} 03^{\prime} 39^{\prime}$ ' sampai $103^{\circ} 13^{\prime} 17^{\prime}$ ' Bujur Timur.

\section{Pengumpulan Data}

Bahan studi pendahuluan mengenai rencana Pembangunan Bendung dan Jaringan Irigasi Batang Asai yang diperoleh dari Balai Wilayah Sungai Sumatera VI, diantaranya

a. Data primer, meliputi survey lapangan, kondisi eksisting dan foto dokumentasi.

b. Data sekunder yang meliputi:

- Data hidrologi data curah hujan di daerah studi, klimatologi, penggunaan lahan, luas DAS dan luas wilayah.

- Peta topografi Kabupaten Sarolangun

\section{HASIL DAN PEMBAHASAN}

\section{Perhitungan Curah Hujan Rencana}

Pada penelitian ini digunakan data curah hujan selama 15 tahun pada stasiun penakar hujan Pulau Pandan. Perhitungan curah hujan rencana menggunakan Metode Gumbel. 
Tabel 1. Data Curah Hujan Kabupaten Sarolangun Stasiun Pulau Pandan Kec.

Limun

\begin{tabular}{|c|c|c|c|c|c|c|c|c|c|c|c|c|c|}
\hline \multirow{2}{*}{ No } & \multirow{2}{*}{ Tahun } & \multicolumn{12}{|c|}{ BULAN } \\
\hline & & JAN & FEB & MAR & APR & MEI & JUN & JUL & AGS & SEP & OKT & NOV & DES \\
\hline 1 & 2002 & 170,00 & 47,30 & 132,50 & 111,50 & 118,90 & 42,50 & 16,90 & 22,80 & 27,10 & 12,90 & 117,40 & 65,30 \\
\hline 2 & 2003 & 546,40 & 298,40 & 133,80 & 563,80 & 182,80 & 150,20 & 132,70 & 240,70 & 138,40 & 216,20 & 505,80 & 267,00 \\
\hline 3 & 2004 & 441,80 & 557,80 & 398,80 & 330,20 & 153,40 & 59,40 & 203,60 & 29,00 & 138,40 & 275,00 & 468,40 & 455,80 \\
\hline 4 & 2005 & 118,70 & 205,00 & 196,50 & 137,70 & 107,00 & 53,10 & 165,20 & 93,00 & 76,00 & 167,20 & 339,70 & 260,00 \\
\hline 5 & 2006 & 345,00 & 249,50 & 235,00 & 311,00 & 251,10 & 119,00 & 154,50 & 43,00 & 107,00 & 38,50 & 305,50 & 182,50 \\
\hline 6 & 2007 & 318,50 & 54,50 & 349,50 & 298,50 & 165,00 & 228,00 & 236,50 & 29,50 & 55,60 & 250,50 & 341,00 & 175,50 \\
\hline 7 & 2008 & 237,00 & 211,00 & 312,50 & 336,50 & 328,00 & 138,50 & 75,50 & 147,00 & 131,00 & 274,50 & 238,50 & 341,00 \\
\hline 9 & 2010 & 381,00 & 479,00 & 512,00 & 242,00 & 275,00 & 148,00 & 339,00 & 150,00 & 373,00 & 140,00 & 362,00 & 142,00 \\
\hline 10 & 2011 & 262,00 & 258,50 & 165,00 & 406,00 & 276,50 & 188,00 & 124,50 & 118,50 & 160,50 & 563,50 & 178,50 & 444,50 \\
\hline 11 & 2012 & 143,00 & 316,00 & 81,00 & 172,00 & 164,00 & 52,00 & 192,00 & 27,00 & 34,00 & 144,00 & 203,00 & 250,00 \\
\hline 12 & 2013 & 182,00 & 190,00 & 170,00 & 155,00 & 164,00 & 90,00 & 108,00 & 25,00 & 127,00 & 97,00 & 214,00 & 165,00 \\
\hline 13 & 2014 & 199,00 & 122,00 & 99,00 & 152,00 & 224,00 & 15,00 & 80,00 & 140,00 & 37,00 & 73,00 & 289,00 & 181,00 \\
\hline 14 & 2015 & 160,00 & 210,00 & 198,00 & 484,00 & 103,00 & 48,00 & 15,00 & 4,00 & 8,00 & 13,00 & 341,00 & 628,00 \\
\hline 15 & 2016 & 344,00 & 450,00 & 349,00 & 293,00 & 248,00 & 156,00 & 20,00 & 47,00 & 33,00 & 133,00 & 200,00 & 19,00 \\
\hline
\end{tabular}

Sumber: Balai Wilayah Sungai Sumatera VI, 2017

Tabel 2. Rekapitulasi Curah Hujan Rencana Periode Ulang (T) dengan Metode Gumbel

\begin{tabular}{ccccccc}
\hline $\begin{array}{c}\text { Periode } \\
\text { Ulang }\end{array}$ & $\mathbf{Y t}$ & $\overline{\mathbf{x}}$ & $\mathbf{Y n}$ & $\mathbf{S n}$ & $\mathbf{S}$ & $\mathbf{X t}$ \\
\hline 2 & 0,3065 & 396,753 & 0,5128 & 1,0206 & & 367,334 \\
5 & 1,4999 & 396,753 & 0,5128 & 1,0206 & & 537,520 \\
10 & 2,2504 & 396,753 & 0,5128 & 1,0206 & 145,544 & 644,546 \\
25 & 3,1255 & 396,753 & 0,5128 & 1,0206 & & 769,341 \\
50 & 3,9019 & 396,753 & 0,5128 & 1,0206 & & 880,060 \\
100 & 4,6001 & 396,753 & 0,5128 & 1,0206 & & 979,628 \\
\hline
\end{tabular}

Sumber: Hasil Perhitungan, 2017

\section{Perhitungan Evapotranspirasi}

Dari hasil analisa dan perhitungan evapotranspirasi dengan metode Penmann Modifikasi diperoleh evapotranspirasi sebagai berikut :

Tabel 3. Rekapitulasi Evapotranspirasi

\begin{tabular}{cccc}
\hline Bulan & $\begin{array}{c}\text { Eto } \\
(\mathbf{m m} / \mathbf{h r})\end{array}$ & Bulan & $\begin{array}{c}\text { Eto } \\
(\mathbf{m m} / \mathbf{h r})\end{array}$ \\
\hline Jan & 3,31 & Jul & 2,60 \\
Feb & 4,49 & Agust & 2,99 \\
Mar & 3,14 & Sept & 3,57 \\
Apr & 2,94 & Okt & 3,94 \\
Mei & 2,74 & Nov & 3,73 \\
Jun & 2,45 & Des & 3,29 \\
\hline
\end{tabular}

Sumber: Hasil Perhitungan, 2017

\section{Perhitungan Curah Hujan Efektif}

Untuk mendapatkan tahun dasar perencanaan didapat dari curah hujan yang diurutkan dari nilai terkecil sampai nilai terbesar. Berikut adalah perhitungan curah hujan efektif : 
Tabel 4. Rekapitulasi Curah Hujan Efektif

\begin{tabular}{|c|c|c|c|c|c|c|c|}
\hline \multirow{2}{*}{\multicolumn{2}{|c|}{ Bulan }} & \multicolumn{2}{|c|}{$\operatorname{Re}(\mathrm{mm} / \mathrm{hr})$} & \multirow{2}{*}{\multicolumn{2}{|c|}{ Bulan }} & \multicolumn{2}{|c|}{$\operatorname{Re}(\mathrm{mm} / \mathrm{hr})$} \\
\hline & & \multirow{2}{*}{$\begin{array}{c}\text { Padi } \\
3,22\end{array}$} & \multirow{2}{*}{$\begin{array}{c}\text { Palawija } \\
5,23\end{array}$} & & & \multirow{2}{*}{$\frac{\text { Padi }}{0,33}$} & \multirow{2}{*}{$\begin{array}{c}\text { Palawija } \\
1,68\end{array}$} \\
\hline & I & & & \multirow{2}{*}{ Jul } & I & & \\
\hline Jan & II & 5,32 & 5,93 & & II & 0,61 & 3,36 \\
\hline \multirow{2}{*}{ Feb } & I & 8,12 & 7,84 & \multirow{2}{*}{$\begin{array}{c}\text { Agu } \\
\text { st }\end{array}$} & I & 1,03 & 4,29 \\
\hline & II & 0,75 & 4,20 & & II & 0,19 & 1,21 \\
\hline \multirow{2}{*}{ Mar } & I & 3,50 & 4,20 & \multirow{2}{*}{ Sept } & I & 0,09 & 3,08 \\
\hline & II & 4,20 & 5,04 & & II & 1,49 & 2,85 \\
\hline \multirow{2}{*}{ Apr } & I & 3,50 & 6,81 & \multirow{2}{*}{ Okt } & I & 1,49 & 3,83 \\
\hline & II & 4,57 & 4,48 & & II & 3,03 & 2,71 \\
\hline \multirow{2}{*}{ Mei } & I & 4,95 & 5,09 & \multirow{2}{*}{ Nov } & I & 4,29 & 5,04 \\
\hline & II & 2,71 & 5,41 & & II & 5,18 & 8,45 \\
\hline \multirow{2}{*}{ Jun } & I & 2,33 & 1,26 & \multirow{2}{*}{ Des } & I & 4,67 & 6,86 \\
\hline & II & 0,09 & 2,94 & & II & 3,03 & 4,81 \\
\hline
\end{tabular}

Sumber: Hasil Perhitungan, 2017

\section{Perhitungan Kebutuhan Air untuk Penyiapan Lahan}

Kebutuhan air untuk penyiapan lahan umumnya sangat menentukan kebutuhan maksimum air irigasi. Hasil perhitungan kebutuhan air untuk penyiapan lahan adalah sebagi berikut :

Tabel 5. Rekapitulasi Kebutuhan Air untuk Penyiapan Lahan

\begin{tabular}{cccc}
\hline Bulan & IR & Bulan & IR \\
\hline Jan & 8,85 & Jul & 8,34 \\
Feb & 9,73 & Ags & 8,61 \\
Mar & 8,72 & Sep & 9,04 \\
Apr & 8,58 & Okt & 9,31 \\
Mei & 8,44 & Nov & 9,16 \\
Jun & 8,23 & Des & 8,83 \\
\hline
\end{tabular}

Sumber: Hasil Perhitungan, 2017

Perhitungan Kebutuhan Air untuk Masa Tanam Padi dan Palawija

Pada penelitian ini diterapkan pola tanam Padi - Padi - Palawija. Perhitungan kebutuhan air di sawah sebagai berikut :

Tabel 6. Rekapitulasi Kebutuhan Air Tanaman

\begin{tabular}{cccccccc}
\hline \multicolumn{2}{c}{ Bulan } & Pola Tanam & $\begin{array}{c}\mathbf{Q} \\
(\mathbf{m} 3 / \mathbf{s})\end{array}$ & \multicolumn{2}{c}{ Bulan } & Pola Tanam & $\begin{array}{c}\mathbf{Q} \\
(\mathbf{m} 3 / \mathbf{s})\end{array}$ \\
\hline \multirow{2}{*}{ Nov } & I & Penyiapan Lahan & 1,30 & \multirow{2}{*}{ Mei } & I & Padi & 0,31 \\
& II & Penyiapan Lahan & 1,06 & & II & Padi & 0,91 \\
\multirow{2}{*}{ Des } & I & Penyiapan Lahan & 1,11 & \multirow{2}{*}{ Jun } & I & Padi & 1,19 \\
& II & Padi & 0,98 & & II & Padi & 1,49 \\
Jan & I & Padi & 0,94 & \multirow{2}{*}{ Jul } & I & Padi & 0,87 \\
& II & Padi & 0,63 & & II & Panen & 0,00 \\
Feb & I & Padi & 0,00 & Ag & I & Palawija & 0,00
\end{tabular}




\begin{tabular}{cccccccc} 
& II & Padi & 1,77 & us & II & Palawija & 0,28 \\
\multirow{2}{*}{ Mar } & I & Panen & 0,00 & Sep & I & Palawija & 0,13 \\
& II & Penyiapan Lahan & 1,21 & t & II & Palawija & 0,19 \\
\multirow{2}{*}{ Apr } & I & Penyiapan Lahan & 1,36 & \multirow{2}{*}{ Okt } & I & Palawija & 0,00 \\
& II & Penyiapan Lahan & 1,07 & & II & Panen & 0,00 \\
\hline
\end{tabular}

Sumber: Hasil Perhitungan, 2017

\section{Perhitungan Debit Andalan}

Untuk perhitungan debit andalan digunakan curah hujan bulanan dengan metode Basic Year pada data ke-m dimana:

$$
\begin{array}{rll}
\mathrm{m} & = & 0,20 \times(\mathrm{n}+1) \\
& = & 0,20 \times(8+1) \\
& = & 1,8 \approx 2
\end{array}
$$

Jadi data yang dipergunakan untuk perhitungan debit andalan adalah urutan ke 2 data curah hujan dari data terkecil. Adapun jumlah air yang tersedia untuk mengairi Daerah Irigasi Batang Asai sebagai berikut :

Tabel 7. Rekapitulasi Debit Andalan dengan Metode Mock

\begin{tabular}{cccc}
\hline Bulan & $\mathbf{Q}(\mathbf{m} 3 / \mathbf{d t k})$ & Bulan & $\mathbf{Q}(\mathbf{m} \mathbf{3} / \mathbf{d t k})$ \\
\hline Jan & 18,43 & Jul & 5,45 \\
Feb & 13,80 & Agust & 2,28 \\
Mar & 10,61 & Sept & 5,44 \\
Apr & 8,78 & Okt & 4,62 \\
Mei & 8,37 & Nov & 8,87 \\
Jun & 5,35 & Des & 7,69 \\
\hline
\end{tabular}

Sumber: Hasil Perhitungan, 2017

Tabel 8. Neraca Air

\begin{tabular}{lccc}
\hline \multicolumn{1}{c}{ Bulan } & \multicolumn{3}{c}{ Kolume } \\
& $\begin{array}{c}\text { Kebutuhan Air } \\
(\mathrm{m} 3 / \mathrm{dtk})\end{array}$ & $\begin{array}{c}\text { Ketersediaan Air } \\
(\mathrm{m} 3 / \mathrm{dtk})\end{array}$ & Selisih \\
\hline Januari & 1,57 & 18,43 & 16,86 \\
Februari & 1,77 & 13,80 & 12,03 \\
Maret & 1,21 & 10,61 & 9,40 \\
April & 2,43 & 8,78 & 6,35 \\
Mei & 1,22 & 8,37 & 7,15 \\
Juni & 2,68 & 5,35 & 2,67 \\
Juli & 0,87 & 5,45 & 4,58 \\
Agustus & 0,28 & 2,28 & 2,00 \\
September & 0,32 & 5,44 & 5,12 \\
Oktober & 0 & 4,62 & 4,62 \\
November & 2,36 & 8,87 & 6,51 \\
Desember & 2,09 & 8,87 & 6,78
\end{tabular}

Sumber: Hasil Perhitungan, 2017 


\section{Perencanaan Petak Irigasi}

Peta ikhtisar umum dibuat berdasarkan peta topografi yang dilengkapi dengan garis-garis kontur dengan skala 1:25.000. Perencanaan jaringan irigasi Batang Asai Kabupaten Sarolangun seluas 1500 Ha tepatnya berada di Desa Berau Kecamatan Cermin Nan Gedang.

\section{Perencanaan Dimensi Saluran}

Perencanaan dimensi saluran dilakukan dengan menganggap bahwa aliran di saluran adalah aliran seragam (uniform flow). Saluran direncanakan berdasarkan rumus Manning/Strickler.

$$
\begin{aligned}
& \mathrm{V}=\mathrm{kR}^{2 / 3} \mathrm{I}^{1 / 2} \\
& \mathrm{~A}=(\mathrm{b}+\mathrm{mh}) \mathrm{h} \\
& \mathrm{P}=\mathrm{b}+2 \mathrm{~h} \sqrt{m^{2}+1} \\
& \mathrm{R}=\mathrm{A} / \mathrm{P}
\end{aligned}
$$

Dimana:

$\mathrm{V}=$ kecepatan aliran $(\mathrm{m} / \mathrm{det})$

$\mathrm{k}=$ koefisien kekasaran saluran dari Strikler $\left(\mathrm{m}^{1 / 3} / \mathrm{det}\right)$

$\mathrm{R}=$ jari - jari hidrolis $(\mathrm{m})$

$\mathrm{I}=$ kemiringan saluran

$\mathrm{A}=$ luas penampang saluran $\left(\mathrm{m}^{2}\right)$

$\mathrm{P}=$ keliling basah saluran $(\mathrm{m})$

$\mathrm{b}=$ lebar dasar saluran $(\mathrm{m})$

$\mathrm{h}=$ tinggi air disaluran $(\mathrm{m})$

$\mathrm{m}=$ kemiringan talud $(1: 1)$

Berikut ini adalah potongan melintang penampang saluran primer :

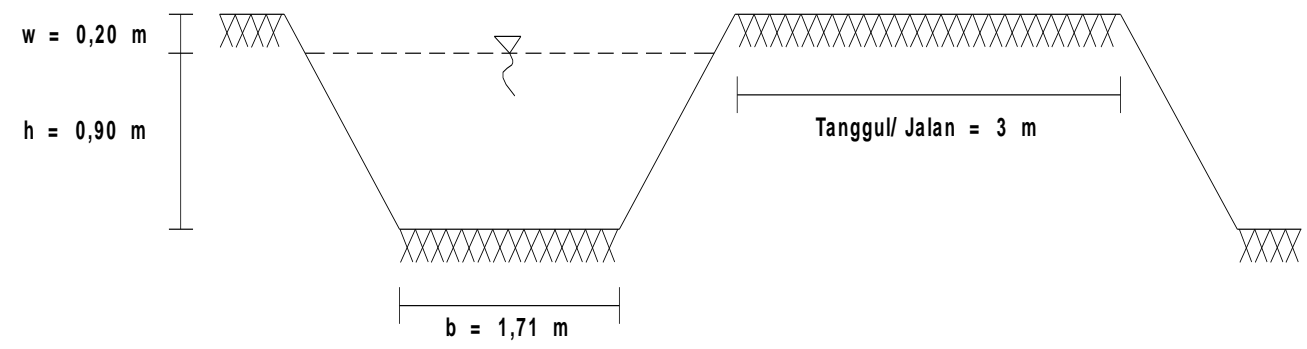

\section{Gambar 1. Potongan Melintang Penampang Saluran Primer}

(Sumber: Data Olahan, 2017)

\section{Gorong-gorong}

Untuk gorong-gorong pendek $(\mathrm{L}<20 \mathrm{~m})$ seperti yang biasa direncanakan dalam jaringan irigasi, rumusnya

Dimana:

$$
\mathrm{Q}=\mu A \sqrt{2 g z}
$$

$\mathrm{Q}=\operatorname{debit}\left(\mathrm{m}^{3} / \mathrm{dt}\right)$

$\mu=$ koefisien debit

$\mathrm{A}=$ luas penampang saluran, $\mathrm{m}^{2}$

$\mathrm{g}=$ percepatan gravitasi $\left(\mathrm{m}^{2} / \mathrm{dt}\right)$

$\mathrm{Z}=$ kehilangan tinggi energi pada gorong-gorong $(\mathrm{m})$ 
Pada perencanaan jaringan irigasi ini, salah satu bangunan pelengkap yakni berupa gorong-gorong untuk mengatasi rintangan (pada perpotongan saluran dan jalan) dengan profil atau bentuk kotak persegi empat, seperti pada gambar berikut:

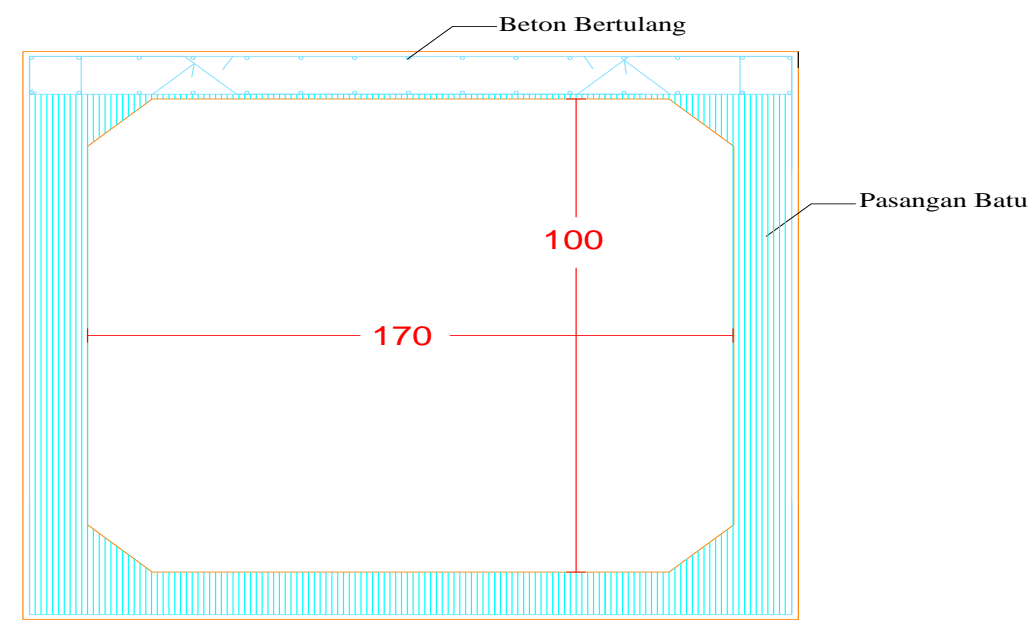

Gambar 2. Dimensi Gorong-gorong

(Sumber: Data Olahan, 2017)

\section{Pintu Sorong}

Salah satu bangunan pengontrol taraf muka air yaitu pintu sorong dengan besi. Bangunan ini dapat digunakan sebagai pengukur debit yang lewat bawah pintu. Persamaan hidraulik pintu sorong (aliran bawah) sebagai berikut:

Dimana:

$$
\mathrm{Q}=\mu \cdot \mathrm{a} \cdot \mathrm{b} \cdot \sqrt{2 g z}
$$

$\mathrm{Q}=\operatorname{debit}\left(\mathrm{m}^{3} / \mathrm{dt}\right)$

$\mu=$ koefisien debit $( \pm 0,80)$

$\mathrm{a}=$ tinggi bukaan pintu $(\mathrm{m})$

$\mathrm{b}=$ lebar bukaan pintu $(\mathrm{m})$

$\mathrm{g}=$ percepatan gravitasi $\left(\mathrm{m}^{2} / \mathrm{dt}\right)$

$\mathrm{z}=$ perbedaan antara tinggi muka air udik dan hilir (m)

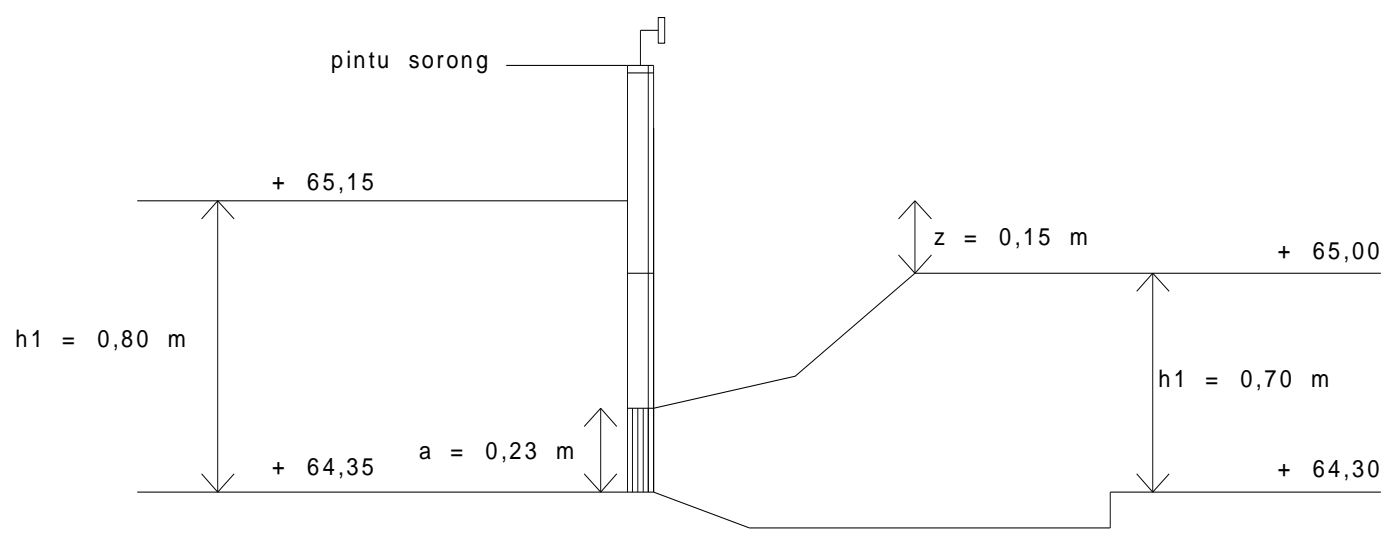

Gambar 3. Potongan Memanjang Pintu Sorong

(Sumber: Data Olahan, 2017) 


\section{SIMPULAN}

Berdasarkan hasil dari analisa dan perhitungan yang telah dilakukan, dapat diambil beberapa kesimpulan sebagai berikut:

1. Dari analisa ketersediaan air dengan Metode F. J. Mock diketahui besarnya debit andalan pada Daerah Irigasi Batang Asai Kabupaten Sarolangun dapat memenuhi kebutuhan air untuk petak sawah yang direncanakan yaitu seluas $1500 \mathrm{Ha}$, maka pola tanam yang diusulkan untuk diterapkan di Daerah Irigasi tersebut adalah pola tanam padi-padi-palawija.

2. Dimensi saluran direncanakan dengan bentuk penampang trapesium. Penggunaan model trapesium dikarenakan lahan masih cukup luas, secara ekonomis lebih menguntungkan dibandingkan penampang persegi empat.

3. Bangunan pelengkap berupa gorong-gorong dan bangunan sadap dengan pintu sorong di setiap cabang saluran.

4. Dengan sumber air berasal dari sungai Batang Asai yang mempunyai luas DPS secara keseluruhan $\pm 1262,4 \mathrm{~km}^{2}$ dan panjang sungai utamanya $\pm 104,1$ $\mathrm{km}$, daerah ini sangat berpotensial untuk mengembangkan petak irigasi $>1500$ Ha beserta jaringan irigasinya untuk mewujudkan harapan Pemerintah menjadikan daerah ini sebagai lumbung padi dan meningkatkan ketahanan pangan nasional.

\section{Saran}

Dengan potensi persawahan yang luas dimana harapan Daerah Irigasi Batang Asai akan menjadi lumbung padi khususnya bagi Kabupaten Sarolangun dan umumnya bagi Provinsi Jambi dapat terwujud untuk itu harus diterapkan pola tanam yang tepat serta perlu diadakan sosialisasi dalam rangka meningkatkan peran serta masyarakat dalam pengelolaan dan pemeliharaan aset irigasi. Perlu kiranya dilakukan kelestarian hutan disekitar sumber air untuk menjaga kestabilan ketersediaan air.

\section{DAFTAR PUSTAKA}

Ansori, Ahmad, dkk. Kajian Efektifitas dan Efesiensi Jaringan Irigasi terhadap Kebutuhan Air pada Tanaman Padi (Studi Kasus Irigasi Samo Kecamatan Rambah Kabupaten Rokan Hulu. Fakultas Teknik Universitas Pasir Pengaraian.

Direktorat Jendral Pengairan. 1986. Standar Perencanaan Irigasi Bagian Penunjang. Bandung: Galang Persada.

Hadihardjaja, Joetata. 1997. Irigasi dan Bangunan Air. Jakarta: Universitas Gunadarma.

Kamiana, I Made. 2011. Teknik Perhitungan Debit Rencana Bangunan Air. Yogyakarta: Graha Ilmu.

Kementrian Pekerjaan Umum Direktorat Jenderal Sumber Daya Air Direktorat Irigasi dan Rawa. 2013. Kriteria Perencanaan Bagian Perencanaan Jaringan Irigasi KP-01. Jakarta: Kementrian Pekerjaan Umum Direktorat Jenderal Sumber Daya Air Direktorat Irigasi dan Rawa.

Kementrian Pekerjaan Umum Direktorat Jenderal Sumber Daya Air Direktorat Irigasi dan Rawa. 2013. Kriteria Perencanaan Bagian Perencanaan Saluran KP-03. Jakarta: Kementrian Pekerjaan Umum Direktorat Jenderal Sumber Daya Air Direktorat Irigasi dan Rawa.

Kementrian Pekerjaan Umum Direktorat Jenderal Sumber Daya Air Direktorat Irigasi dan Rawa. 2013. Kriteria Perencanaan Bagian Bangunan KP-04. 
Jakarta: Kementrian Pekerjaan Umum Direktorat Jenderal Sumber Daya Air Direktorat Irigasi dan Rawa.

Ludiana, dkk. Jurnal Evaluasi Kenerja Jaringan Irigasi Bendungan Tilong Kecamatan Kupang Tengah Kabupaten Kupang. Kupang: FST Undana.

Mawardi, Erman. 2007. Desain Hidraulik Bangunan Irigasi. Bandung: Alfabeta.

Prabawanti, Silvi. 2015. Studi Perencanaan Jaringan Irigasi dan pola Operasi Embung Kokok Koak Daerah Irigasi Kokok Koak Lombok Timur. Malang: Fakultas Teknik Universitas Brawijaya.

Ramadhan, Fahrol, dkk. Evaluasi Kinerja Saluran Jaringan Irigasi Jeuram Kabupaten Nagan Raya. Medan: Departemen Teknik Sipil Universitas Sumatera Utara.

Sosrodarsono, S dan Kensaku Takeda. 1999. Hidrologi untuk Pengairan. Jakarta: PT. Pertja.

Wesli. 2008. Drainase Perkotaan. Yogyakarta: Graha Ilmu. 